\title{
Ciudad, espacio y ciberespacio en la ciencia ficción chilena reciente: Tres versiones del laberinto*
}

\author{
City, space and cyberspace in recent chilean science fiction: \\ Three versions of the labyrinth
}

Macarena Areco

Pontificia Universidad Católica de Chile. Chile

mareco@puc.cl

\section{RESUMEN}

Indagar en los modos de representación del espacio en tres novelas de ciencia ficción chilena, publicadas desde fines de la década de los ochenta hasta ahora, es el objetivo de este artículo. El análisis revela que el horizonte imaginario de los relatos considerados se desplaza desde la ciudad ghetto -El ruido del tiempo (1987) de Claudio Jaque- al escenario totalitario de la ciudad, del ciberespacio y del cuerpo colonizado por las tecnologías informáticas - Ygdrasil (2005) de Jorge Baradit-, pasando por la urbe apocalíptica, en vías de desintegración del bicentenario -2010: Chile en llamas (1998) de Darío Oses-.

Palabras claves: Ciencia ficción chilena, ciberespacio, tecnologías informáticas, globalización.

\section{ABSTRACT}

The objective of this paper is to inquire into the modes of representation of space in three chilean science fiction novels published since the end of the eighties. The analysis reveals that the imaginary horizon of the stories could be considered as thought in continuum from city-ghetto - El ruido del tiempo (1987) by Claudio Jaque- to a totalitarian scene of the city, the cyberspace and the body colonized by information technologies - Ygdrasil (2005) by Jorge Baradit-, including the apocalyptic metropolis, in the process of disintegration of the bicentenary -2010: Chile en llamas (1998) by Dario Oses-.

Keywords: Chilean science fiction, cyberspace, information technologies, globalization.

Recibido: 27-10-2008 Aceptado: 04-11-2008

*Este trabajo forma parte de la investigación posdoctoral financiada por el Fondo Nacional de Desarrollo Científico y Tecnológico titulada "Tramas e imaginarios sociales en la ciencia ficción chilena reciente”, Proyecto Fondecyt No 3080043. 


\begin{abstract}
A pesar de su temporalidad futurista, si leemos la ciencia ficción como un 1 género simbólico ${ }^{1}$, los relatos pertenecientes a esta modalidad, más que entregar imágenes del futuro, dan cuenta del presente, aunque no se trata de un reflejo, sino que de una refracción con diversos grados de deformación ${ }^{2}$. En el presente trabajo examino una porción específica de ese imaginario -el espaciotal como aparece en tres novelas pertenecientes al subgénero publicadas en los últimos veinte ańos por autores chilenos, estableciendo, cuando sea pertinente, relaciones con algunas configuraciones características del territorio nacional y global de las décadas finales del siglo XX y la primera del XXI. El análisis revela que el horizonte imaginario de los relatos considerados se desplaza desde la ciudad ghetto en El ruido del tiempo (1987) de Claudio Jaque, al escenario totalitario de la ciudad, del ciberespacio y del cuerpo colonizados por las tecnologías informáticas - Ygdrasil (2005) de Jorge Baradit-, pasando por la urbe apocalíptica, en vías de desintegración del bicentenario, en 2010: Chile en llamas (1998) de Darío Oses. En cada uno de estos estadios, el laberinto aparece como una forma recurrente de configurar los lugares, que determina alternativas diversas en términos de voluntad y de capacidad de acción de los personajes.
\end{abstract}

\title{
I. EL RUIDO DEL TIEMPO
}

En la primera novela del corpus, El ruido del tiempo, la tendencia a la segregación social propia de la ciudad de Santiago aparece llevada a sus extremos, lo que da como resultado, en la parte inicial del relato, un espacio partido en dos: por un lado, la ciudad de Cinac, suerte de ghetto al que son enviados "los inactivos", y, por el otro, el centro del poder, Coridra, formado a su vez por otro centro, el Búnker subterráneo ${ }^{3}$. Mientras esta segunda urbe, la del poder,

${ }^{1}$ Esta visión es planteada por Borges en su prólogo a las Crónicas Marcianas de Ray Bradbury publicadas por Minotauro en 1955: "Toda literatura (...) es simbólica; hay unas pocas experiencias fundamentales y es indiferente que un escritor, para transmitirlas, recurra a lo 'fantástico' o a lo 'real' (...) Bradbury ha puesto sus largos domingos vacíos, su tedio americano, su soledad, como los puso Sinclair Lewis en Main Street" (1996: 29).

${ }^{2}$ Según Frederic Jameson el subgénero "no nos entrega imágenes del futuro (...) sino que más bien desfamiliariza y reestructura nuestra experiencia del presente" (1982: 151). El concepto de refracción está tomado de Voloshinov: "La existencia reflejada en el signo, no tanto se refleja propiamente como se refracta en él” (citado en Asensi, 2003: 461), mientras que el de deformación, se relaciona con la descripción hecha por Freud en La interpretación de los sueños. Ver capítulos III, IV y VI.

${ }^{3}$ Pueden leerse aquí referencias al Santiago de los setenta y ochenta. Así por ejemplo, Jaime Lizama (2007) hace referencia a los desplazamientos de la población más pobre hacia el exterior 
apenas se describe, el relato se centra en Cinac, en donde un grupo de jóvenes liderado por Long y Rik planea una rebelión ${ }^{4}$. Cinac es una distopía que, bajo el epíteto de "territorio de gratuidad", se disfraza de utopía. Como tal hiperboliza los rasgos de las sociedades disciplinarias: el encierro, el higienismo llevado a su máxima expresión, la esterilización, más un detallado set de prohibiciones y un sistema de vigilancia que se piensa sin fisuras. Como ciudad-cárcel, su frontera está marcada por una línea blanca que se alza como una pared de fuego invisible que desintegra al que intente traspasarla5. Como ciudad panóptica, está sometida a la más estricta vigilancia. No obstante, se diferencia de un campo de concentración por la relativa comodidad y las "libertades" de que gozan sus habitantes. En Cinac, "territorio de gratuidad", los inactivos reciben una buena comida completa diariamente, además de dos cervezas por jornada y de controles de salud mensuales sin costo. Son asimismo obsequiados con productos provistos por la industria cultural que equipos creativos especiales preparan para ellos. Además, disfrutan de una ilimitada libertad sexual, la cual, contra las apariencias, tiene una productividad más allá de la infertilidad a que los cinacianos han sido condenados, al ser usada como una forma de camuflaje que permite atraer la atención de las cámaras y realizar los encuentros que sí están prohibidos: los políticos. Así lo revela la escena erótica, al comienzo de la novela, que Mara y Hono montan en la calle para que Long y Rik puedan

que generan una suerte de límite: "las erradicaciones de los bárbaros desde los conventillos y cités santiaguinos hacia comunas semirrurales y oscuras, suficientemente distantes del centro; erradicaciones y re-localizaciones de viviendas en las periferias, esto es, fuera de la frontera citadina y ciudadana, alejados del centro del poder y del bien ciudad" (23-4). La tendencia anterior se potencia por la política de segregación propiciada por el gobierno militar, cuyo objetivo fue "acotar los bolsones de pobreza (...) juntar y concentrar más adecuadamente a los pobres” (27). La Pintana, comuna creada en ese periodo, se asemeja al territorio ficticio de Cinac, como "territorio de destino de las erradicaciones y del destierro de los pobres y de la 'limpieza urbana' de las comunas del barrio alto", que se convierte "en una comuna perfectamente periférica, implacablemente segregada en su homogeneidad" (27). Por otra parte, su descripción de "una ciudad fantasmagórica, irreal, periférica (...) en penumbras, superpuesta a la ciudad institucional, un suburbio para el olvido" (24), también recuerda a Cinac. El búnker fue un término muy usado para referirse a la casa que se construyó Pinochet en el sector de Lo Curro a mediados de los ochenta.

${ }^{4}$ Cinac es una ciudad uniformizada, casi sin marcas que la estratifiquen, en que los pocos hitos urbanos que la esbozan hacen referencia a Santiago: el estadio, que fue centro de detención en el pasado, una iglesia cuidada por el padre Franzo, a la que nadie asiste, salvo los jóvenes que planean la rebelión, y el Metro, en desuso, cuyos túneles serán el emplazamiento del levantamiento contra Coridra.

${ }^{5}$ En este sistema carcelario, las normas están claramente establecidas: "Asistir a los comedores constituía el único acto obligatorio en la ciudad de los inactivos. Lo demás eran prohibiciones. Prohibido fabricar y usar herramientas, prohibido bailar, prohibido comerse los cadáveres, prohibido cantar a dúo. Prohibido. Y los cinacianos conocían el valor de esos interdictos porque habían visto a demasiados rebeldes desaparecer sin rastros" (32). 
entrar en la iglesia a recibir la información del padre Franzo, recién llegado de Coridra, la cual es un espectáculo, como lo demuestra el que la pareja cuente con un espectador con "distancia crítica" que los juzga en términos estéticos: "Desde arriba del edificio, un viejo los observaba sin intriga, evaluando el arte de ambos" $(22)^{6}$.

Esta escena inicial entrega una pista respecto a uno de los rasgos más productivos de la novela: la profusión de usos desviados que los jóvenes subalternos hacen de las tecnologías de disciplinamiento practicadas por Coridra. Así, el empleo de la sexualidad como modo de control ${ }^{7}$ es invertido, al ponerla al servicio de la rebelión, mientras que la transformación de lo que antes "era vivido directamente(...) en una mera representación", según la expresión con la que Debord explica la sociedad del espectáculo ${ }^{8}$, aparece como una estrategia de huida de la ciudad ghetto. De esta manera, en el aparente estado de interdicción y marginación al que Coridra los obliga, los jóvenes que, como en la canción del grupo de rock Los Prisioneros parecen gastar el tiempo "entre patadas a las piedras y tragos de cerveza" (40) -esto se muestra en la primera aparición de Long y Rik-, en realidad organizan la rebelión, usando a su favor las formas de control que el poder ha dispuesto en su contra?.

En la segunda parte del relato, que empieza cuando el complot se pone en marcha, el espacio y los personajes no pueden escapar a la dualidad que es una de sus leyes ${ }^{10}$ : el grupo de cinco jóvenes liderados por Long, que ha logrado huir

${ }^{6}$ Como se sabe, la Iglesia Católica chilena jugó un papel importante en la lucha contra la dictadura de Pinochet.

${ }^{7}$ En "El sujeto y el poder", Michel Foucault (2001) se refiere a tres modos por los cuales los seres humanos son constituidos en sujetos, a los que llama objetivaciones: 1) modos de investigación que tratan de darse a sí mismo el estatus de ciencia, por ejemplo, la gramática, la economía y la biología; 2) las "prácticas divisorias", según las cuales "el sujeto, o bien se divide a sí mismo o es dividido por los otros", por ejemplo, el loco y el cuerdo, el enfermo y el sano, el criminal y los buenos muchachos, y 3) la sexualidad, como modo en que los seres humanos han aprendido a reconocerse a sí mismos como sujetos de "sexualidad" (241-242). En la teoría foucaultiana, el sujeto es una construcción del poder, el cual "categoriza al individuo, le asigna su propia individualidad, le ata a su propia identidad, le impone una ley de verdad sobre sí que está obligado a reconocer y que otros deben reconocer en él. Es una forma de poder que hace sujetos individuales. Hay dos significados de la palabra sujeto: sujeto a alguien por medio del control y de la dependencia y, por otro, sujeto ligado a su propia identidad por conciencia o autoconocimiento. Ambos significados sugieren una forma de poder que subyuga y sujeta" (245).

${ }^{8}$ Ver el primer apartado de La sociedad del espectáculo de Guy Debord (2002).

${ }^{9} \mathrm{La}$ canción de Los Prisioneros (1986) se llama "El baile de los que sobran" y es una crítica a las desigualdades del sistema educacional chileno que tiene como resultado la marginación de los jóvenes de sectores populares. Su título da cuenta de un sentimiento de exclusión que es similar al de los jóvenes de Cinac, quienes son además "prisioneros" en la ciudad ghetto.

${ }^{10}$ Que puede vincularse con la polarización del referente. Así por ejemplo, dice Lizama sobre Santiago: "Resultaba evidente que una ciudad que erradicaba y localizaba a los sectores populares 
de la ciudad con la intención de abrir las fronteras, es capturado y enviado a una cárcel espacial. Allí el territorio travestido de utopía que es Cinac se cristaliza en una distopía indisimulada, en un infierno circular estructurado como un panóptico, donde a la vigilancia permanente se le suman los castigos más crueles. Pero, más allá de esta representación mitad dantesca mitad foucaultiana de la nave, interesa destacar que, para cada círculo infernal, la novela enfatiza el contrapunto que se produce entre las técnicas de sujeción y las respectivas estrategias de resistencia. Así, los ancianos. Así el harén. Así los rematados. En el caso de los viejos que vegetan al ritmo de las comidas y las sirenas, que han renunciado a las palabras, y que sólo se comunican mediante "el idioma de las arrugas" (124), es precisamente el silencio lo que los salva, según le explica el jefe, llamado el arquitecto, al rebelde Hono: "Nos acusábamos unos a otros de haber cedido más. Las palabras se hicieron insoportables, y debemos sobrevivir, mantener viva la esperanza: es lo único que justifica haber cavado nuestras tumbas" (132-33). Un lenguaje que genera, a partir de su propia abolición, una comunicación que escapa a la significación ${ }^{11}$, como una estrategia de resistencia desarrollada desde la precariedad, representada por el idioma de las arrugas.

"El harén", donde es confinada Nuria, es otro ejemplo de la carencia a que son sometidos los rebeldes, en este caso la mujer del grupo: "una sala amplia, de cuyo techo pendían casi a ras de suelo decenas de jaulas donde se columpiaban mujeres como aves desplumadas. Las más nuevas estaban desnudas, pero con el tiempo conseguían retazos de tela que los guardias sacaban de los mamelucos de los muertos y confeccionaban tiras y cinturones con los que aumentaban su atractivo" (117). En esta suerte de prostíbulo reina Vaxa, la favorita de los jefes, cuyo liderazgo es explicado como el resultado de su capacidad de resolver necesidades elementales en el contexto de la precariedad extrema: "la mayoría de las reclusas (...) apreciaban porque a menudo obtenía favores que otras no habían logrado: una curación en la enfermería para la elegida por un guardia violento, un baño para alguna que llevara mucho tiempo desechada, un descanso para una nueva demasiado requerida" (117-118). En este espacio, donde los requerimientos mínimos son negados, la rebelde Nuria logra, gracias a su relación amorosa con el comandante Arso, posibilitar la liberación de la nave. Como dice el narrador, una vez que Nuria ha conseguido trasladarse al camarote del comandante: "Allí, con geometría de araña, Nuria tejió su red: un delicado encaje cuyos

en las periferias (...) hacía, al mismo tiempo, inviable una visión más integrada de su desarrollo y crecimiento: se imposibilitaba de pensarse con cierta coherencia” (2007: 19).

${ }^{11}$ Ver el análisis que Deleuze y Guattari (2001) hacen del sonido en la obra de Kafka, en Kafka: Por una literatura menor, pp. 14 y ss. 
primeros hilos se habían trenzado en las jaulas del harén" (180).

Por otra parte, en la celda de Exos, la de los presos rematados, el jefe absoluto es Cast, un ex actor de cuyo talante, tan histriónico como salvaje, dan cuenta sus vestimentas: "andaba con la parte superior del mameluco colgando de la cintura como una cola y con el torso cubierto por un chaleco de piel humana sin mangas ni botones" (134). En este contexto, los signos del poder son primarios y sus formas de sustentación, literales. Así, Cast mantiene un espacio vacío a su alrededor que todos respetan y se sienta "sobre las espaldas de alguno de los de su banda, quienes se turnaban con ese fin" (134). No obstante su elementalidad, el narrador se encarga de marcar la productividad de su ejercicio del poder, pues el orden establecido por Cast es el que ha permitido la sobrevivencia de sus compañeros de celda: "los presos (...) no sentían las órbitas en torno a la Tierra; el tiempo se marcaba con luces y sirenas. Al cabo de sus ilusiones (...) adoptaban la esfera como su territorio definitivo. Cast fracturaba ese letargo. Introducía momentos fecundos en que algo cambiaba, y la inercia parecía interrumpirse" (146). El carácter vital de este mandato se manifestó en toda su crudeza en el periodo de aislamiento, cuando Cast elegía a los que serían el alimento de los otros, con lo que salvó al colectivo. Como dice el narrador: "Cast distribuía las partes en aras de la supervivencia. Su poder radicaba en la fuerza, y se ejercía en la distribución” (146).

Paralelamente al espacio de la cárcel y a las formas de resistencia social que en él se generan ${ }^{12}$, se describe el de los rebeldes en Cinac, quienes han bajado a los túneles del Metro para organizar la lucha contra Coridra. En este lugar oscuro, húmedo, precario, donde los personajes también practican el canibalismo ${ }^{13}$, la insubordinación prospera hasta terminar venciendo. Lo que decide el triunfo es la idea de Rik de construir un laberinto -en cuya descripción nuevamente destaca la precariedad, en este caso alimenticia: "El laberinto fue una tripa hambrienta”-, que conducirá a los rebeldes a través de un trazado tortuoso a las puertas del Búnker.

${ }^{12}$ En otro artículo, actualmente en preparación, centro el análisis en las formas de resistencia ejercidas por los personajes en esta novela.

${ }^{13}$ En un artículo publicado en las actas de JALLA 2008, Sebastián Schoennenbeck analiza la antropofagia en Casa de Campo de José Donoso como un trompe l'eil o una simulación con que la familia Ventura oculta la explotación a que ha sometido a los nativos. Distante de la perspectiva burguesa, representada por los terratenientes de la novela de Donoso, en el relato de Jaque la práctica del canibalismo por parte de los rebeldes es mencionada al pasar, como un imperativo, podríamos decir, de precariedad, que se subentiende y que no amerita mayor cuestionamiento. "Bajo la tierra había lo necesario: desde la electricidad de los cables del Metro (...) hasta la ratas que habían proliferado, y la carne de los muertos conservada en sales que la secaban, y las aguas que corrían por las paredes (...) Las profundidades eran fértiles" (225). Un poco más adelante se dice que el padre Franzo "enterró los tres cuerpos gaseados e incomibles" (226). 
Como explica Umberto Eco, existen tres tipos de laberinto: el clásico, que es lineal, con un itinerario único; el manierista, con forma de árbol binario, donde hay muchos recorridos posibles, pero sólo una salida; y el hermético o rizomático, definido por la multiplicidad de conexiones y por su carácter cambiante:

Su forma más intuitiva es la de la red ferroviaria, donde no solamente todo punto está conectado con varios otros puntos, sino que nada impide que se establezcan, entre dos nudos, nuevas uniones, e incluso entre los que no estaban unidos antes. No obstante, lo que diferencia al rizoma de la red ferroviaria es que en teoría el primero no tiene límites porque no se extiende sobre un territorio definido y limitado: es el rizoma en sí, en su forma abstracta, el que define los territorios. No vale la pena preguntarse si el rizoma es finito e ilimitado, o limitado pero infinito: lo esencial es que no tiene exterior y por consiguiente no tiene fronteras. Cada ruta puede ser la correcta, siempre y cuando uno quiera ir hacia donde va y cada punto puede estar unido a cualquier otro punto. El rizoma es por ende el lugar de las conjeturas, de las apuestas, de los azares, de las reconstrucciones, de las inspecciones locales descriptibles, de las hipótesis globales que deben ser continuamente replanteadas, pues una estructura en rizoma cambia de forma constantemente (1987).

A este último tipo pertenece el laberinto que los rebeldes construyen en el Metro, debido a su carácter complejo y cambiante: "Los túneles eran tan intrincados, tan llenos de curvas, tan sorprendentes que de pronto se derrumbaban adelante, de pronto atrás, de pronto separaban una columna en dos" (229). Su movilidad rizomática es justamente la que provoca la desorientación fatal de los hombres de Coridra: "En el laberinto, en la oscuridad en que de pronto eran abandonados los túneles, en los derrumbes que los del equipo de Rabel provocaban, ahí fallecieron vigilantes y jinetes, extraviados, murieron de llanto y de perdidos, porque no encontraban a los cinacianos, porque no encontraban los caminos de retorno" (229).

El laberinto, como modo de representación del espacio se repite, como se ha dicho, en las tres novelas analizadas. No obstante, solo en El ruido del tiempo ha sido construido voluntariamente, como parte de una estrategia de lucha que permite el triunfo de los rebeldes. De ahí que el relato de Jaque sea el único que concibe a lo rizómatico de manera similar a Deleuze y Guattari, como una línea de fuga, que permite encontrar nuevas salidas ${ }^{14}$. Este potencial se pierde por completo en los otros dos relatos que analizo más adelante.

${ }^{14}$ Deleuze y Guattari se cuidan, no obstante, de las valoraciones absolutas y consideran la posibilidad de desarrollos rizomáticos despóticos, que es lo que aparecerá más adelante en el análisis Ygdrasil. Ver "Rizoma”, en Mil mesetas (2006: 9-32). 
A continuación del triunfo en los túneles, la novela relata el ordenamiento que construye Long en la cárcel espacial, después de la caída de Coridra, la que debe hacer un largo trayecto de 49 años antes de volver a la ciudad, sin que sus tripulantes sepan que ésta ha sido destruida. Ni utopía trasvestida ni distopía, la nave liberada es una imagen a escala de una polis autocrática y planificada centralmente, dirigida por un líder carismático, con una policía secreta, una oposición creada y manipulada por el poder, así como centros productivos, educativos y artísticos comandados monolíticamente. Incluso la reproducción, lograda gracias a la llegada de una mujer que no alcanza a ser esterilizada y a las técnicas del médico que había torturado a Long en la cárcel, el Doc, responden a la planificación autocrática. No obstante, la utopía acecha desde el espacio exterior y se presenta en la forma de un planeta deshabitado muy parecido a la Tierra -"Tenía el mismo color azul, la misma seducción de espejismo" (299)-, que se ve desde la nave y al que Long se niega a acercarse, debido a que su misión es regresar a destruir el Búnker. Para vencer "la ilusión" (302) y asegurar el regreso a Coridra, Long ordena cerrar las ventanas, con lo que se inician los tiempos del eclipse "como los poetas llamaban al cierre de las ventanas" (310). Los veteranos del espacio terminan regresando así, después de casi medio siglo, a Ganam, una de las dos ciudades fundadas por los cinacianos (la otra es Asores), una suerte de "mundo feliz", donde gobiernan "los administradores", entre ellos Rik, con implantes cerebrales que les permiten dominar sus emociones, y se construyen seres humanos artificiales. Estos son, como dice Ange, una de las antiguas rebeldes, que les teme y desprecia, "el hombre nuevo al que aspirábamos" (152).

Huida al espacio, renuncia a la utopía y regreso a la Tierra marcada por la dualidad, tanto en el territorio como por el tipo de seres que lo habitan, es la trayectoria dibujada en El ruido del tiempo. Al término de la novela Rik y Long se encuentran en una suerte de final feliz donde la posible divergencia entre los dos grupos -los que se quedaron y los que se vieron obligados a navegar por el espacio- se disuelve en el acuerdo propiciado por la memoria de la precariedad inicial (el patear latas de cerveza vacías), aunque persiste la polaridad entre los "naturales" y los "artificiales". También permanece la impresión de que la utopía -como en el cerrarse de las ventanas de la nave que ha provocado el oscurecimiento del mundo- ha quedado fuera del foco narrativo y, por tanto, de lo posible. En algún lugar del camino largo de la rebelión algo parece haberse perdido y ya no parece posible recuperarlo. 


\section{2010: CHILE EN LLAMAS}

Como dice Jaime Lizama en su ensayo sobre la capital, el Santiago de los noventa "es una ciudad caótica, desordenada, irritable, al borde del colapso apocalíptico de fines de siglo" (2007: 17). La novela de Darío Oses, publicada en 1998, vuelve literal este lugar común, ya que el Santiago que relata es una distopía neoliberal en la que se lleva a sus máximas posibilidades el proceso de liberalización de la economía iniciado por el gobierno militar y la globalización, sólo que en la ficción la ciudad no se limita a estar en el borde, sino que se da el paso adelante y se produce el anunciado fin de mundo. De esta manera, lo que la novela pone en escena es un imaginario apocalíptico y tanático, que representa a la ciudad en un grado de degradación tal que, más allá de dos breves paréntesis utópicos, desautorizados sin demora, todos los caminos se han cerrado y sólo queda sucumbir al vacío ${ }^{15}$.

El relato da cuenta de dos espacios: uno intraciudadano y distópico, el de la urbe en ruinas que es Santiago, marcado por la muerte de "el General", un anciano al que pocos recuerdan, y por un partido de fútbol en que la selección nacional se enfrenta a Perú; y otro extraciudadano, surgido de la huida al campo, donde operan dos utopías: la restauración de una antigua hacienda y el feminismo.

Respecto a lo primero, Santiago es una ciudad en proceso de disolución, sumida en la bruma y castigada por los rayos ultravioletas, donde la basura se amontona por todas partes y cuyos habitantes, idiotizados por la cesantía, la droga legal, el sexo virtual, los espectáculos mediáticos y la manipulación del sentimiento nacional, son incapaces de imaginar y menos de intentar construir una ciudad mejor, presentándose como única expectativa el escape ilusorio ${ }^{16}$.

Las causas de la descomposición son principalmente de dos órdenes, el económico y el mediático. Después de que han sido explotados todos los recursos naturales ${ }^{17}$ y el país se asemeja a "un largo hueso roído" (37), la economía

${ }^{15}$ La lectura de la novela carece de sorpresas, con lo cual coincide la escasa crítica. Por ejemplo, Carolina Ferrer (2005) señala que "La distopía propuesta por Oses presenta un fin de mundo sin posibilidad alguna de supervivencia; visión congruente con la baja complejidad tanto de los personajes como de los acontecimientos narrados y que resuena visiblemente con la linealidad de la estructura narrativa”. Escuetamente, Marcelo Novoa, en su antología Años luz. Mapa de la ciencia ficción en Chile opina que "Darío Oses (...) se muestra obvio, al profetizar el triunfo del modelo post-liberal" (2006: 25).

${ }^{16} \mathrm{La}$ ciudad es representada según los rasgos del ciberpunk: fragmentación, alta tecnología mezclada con desechos y basura. Lo mismo el sujeto, al que la radiación ultravioleta obliga a llevar la marca del personaje del género, los anteojos de sol.

${ }^{17} \mathrm{La}$ cordillera se ha convertido en un "cadáver seco y vaciado de sus venas minerales" (26). 
nacional es sometida a un proceso de "reconversión", basado en tres pilares: la liberación de impuestos al capital, la legalización de la droga y la privatización de todo, incluida la totalidad de la educación universitaria y la defensa. Se ha logrado así, como proclaman orgullosos los políticos neoliberales, que Chile sea "el primer país del mundo en llegar al fin de la Historia" (93). La ciudad poshistórica no necesita de las personas - "Para la economía reconvertida el hombre era un recurso desechable y desechado" (129)-, con lo que cunde la cesantía, el hedonismo, la falta de sentido y la anomia. De ahí que, al empleo masivo de la droga despenalizada como forma de control social, se sume una industria cultural activa como la contracara necesaria del capitalismo financiero. La cúspide de la pirámide de la entretención -que incluye video juegos, estilos musicales y sexo virtual- es el fútbol, que pervive como el último bastión masivo del sentimiento nacional. El otro es el escuálido regimiento Patria Nueva, falto de recursos y de prestigio, del que forma parte el inocente protagonista, el alférez Avelar, encargado de los rituales nacionales, luego de que la seguridad ha sido privatizada y ha quedado en manos de la Corporación Cóndor.

La disolución de la ciudad provocada por la alianza entre economía y espectáculo es sinécdoque de una disolución más amplia, la de la nación, la cual ha operado una regresión hacia una sociedad preilustrada, donde proliferan la brujería y el drama pasional, el racismo y la violencia. La ciudadanía ha devenido tribu, como lo demuestra la descripción del último partido de fútbol, entre la selección nacional y la peruana, donde la barra se convierte en horda -"El bombo volvió a sonar llamando a los combatientes a recomponer filas. Se escuchaban otra vez los roncos rugidos de la tribu" (44) - y cuyo desenlace es el asesinato de todos los jugadores. Por ser el fútbol el último soporte de la nación, la derrota de la selección nacional opera la desintegración del país: "la derrota hacía no poder creer en el fútbol, la última creencia en un país que se estaba esfumando" (47).

La ciudad, en llamas, se representa como apocalíptica, por ejemplo, en la siguiente descripción del Metro:

Varios fuegos mortecinos alumbraban apenas los rincones de aquella estación del Metro. Alrededor de las pobres llamas se apretujaban sombras de hombres, niños y perros que habían bajado a los andenes en busca de refugio (...).

Debía haberse roto una cañería porque el piso estaba anegado, lo que hacía aún más difícil la marcha en la oscuridad (157).

Cuando se inicia el desastre, el político de derecha moderada al que súbitamente se nombra Presidente de la República porque el elegido se encuentra perdido en el exterior, lee la obra de Gibbon sobre la caída del Imperio Romano. 
Las únicas alternativas que quedan en el caos son las huidas temporal y espacial. La primera consiste en la regresión nostálgica hacia el pasado realizada por Alvear, quien vive un mundo aparte gracias a su admiración por el Ejército y por los objetos de la cultura popular de la primera mitad del siglo XX. La huida espacial considera dos alternativas extraciudadanas: la proyección hacia la hacienda y la negación radical tanto del apocalipsis urbano como de la regresión conservadora, operada por un grupo de mujeres en alianza con los bandoleros enemigos de la hacienda. La primera es el resultado de los esfuerzos del político conservador Juan Antonio Eyzaguirre, quien, financiado por la corporación global Expansión, reconstruye la hacienda Corazón de Jesús con la intención de "volver a los orígenes" $(111)^{18}$. Los pocos que regresan relatan que se trata de una pesadilla. Así, la primera utopía premoderna de la novela es descartada como distopía. La segunda alternativa a la urbe son los llamados pueblos de las afuerinas, ubicados en pequeñas ciudades del valle central despobladas por la caída de las exportaciones de productos del campo, en donde las trabajadoras temporeras han creado pequeños grupos con talleres artesanales y agricultura de subsistencia, en "una nueva forma de vida comunitaria que nacía en medio de la desintegración de todas las sociedades" (147). Esta segunda utopía es considerada imposible por las propias feministas: "Lupe y Raquel sabían que a lo largo de la historia esos experimentos de establecer comunidades de vida libre habían sido efímeros parpadeos, rápidamente reprimidos y ahogados" (175).

Esta imposibilidad adelanta lo que será la destrucción del grupo de las afuerinas llevada a cabo por los hombres de Eyzaguirre y es un primer indicio de que en 2010: Chile en llamas no hay alternativas para imaginar el futuro, ni dentro de la modernidad, en una nueva etapa, que pudiera ser la consolidación de su proyecto inconcluso, o en un más allá, en que fuera posible poner en escena pactos sociales diversos. Esta incapacidad de imaginar no sólo una utopía sino que cualquier tipo de escape factible es la explicación del abrupto final de la novela, que ocurre cuando, después de llegar a la hacienda buscando el cadáver del General, el grupo liderado por el alférez (formado por dos jóvenes cercanas a las feministas y por un mercenario) debe recorrer un laberinto que lo conduce a un frigorífico, donde encuentran los restos del dictador. Aunque por la descripción de una de las mujeres podríamos pensar que se trata de un rizoma - "Raquel comentó que estaban atrapados en una especie de laberinto sin centro"

18“La hacienda chilena fue el núcleo ordenador de la sociabilidad de este país -declaró Eyzaguirre-. Por eso hay que volver a ella si se quiere reconstruir el orden destrozado por la orgía" (112). Se trata de un proyecto premoderno, como incluso se explicita: "la Hacienda Corazón de Jesús, primer paso de un proyecto por ruralizar a Chile y ponerlo en el buen camino que perdió al encandilarse con la modernidad" (112). 
(182)-, Alvear lo niega: "El alférez recordó haber leído que todo laberinto tiene un centro, a veces tan difícil de encontrar que parece que no existiera. Sabía que en esos casos, la mejor forma de hallar el centro oculto es avanzar en línea recta" (182). Se trata así, si seguimos las distinciones de Eco, de un laberinto clásico o lineal, el cual se caracteriza, como se ha dicho, por el itinerario único: "De ahí -dice Eco- que pueda ser metáfora de la fatalidad y de la necesidad pero no metáfora de la complejidad y de la no-identidad de los recorridos". Si bien una construcción de este tipo tiene un recorrido fijo, lo que hace relativamente fácil la salida, es también una alternativa cerrada, en la medida en que el trayecto es entendido como destino. Además, el laberinto posee un centro, en el que se encuentra la figura monstruosa pero al mismo tiempo atrayente del Minotauro, que puede volver imposible el egreso. En la novela, el General es el monstruo que encarna una identidad nacional monolítica y estática, congelada, entendida al mismo tiempo como el origen y el destino de la nación. El dictador al que conduce el laberinto de la hacienda configura una autodefinición monstruosa que produce al mismo tiempo fascinación y muerte, atracción e imposibilidad de huida. Por ello los personajes no podrán escapar del impulso tanático de la identidad nacional ineludible. De ese modo lo describe el narrador: "El hielo los seducía con su promesa de sueño eterno, los invitaba a unirse a la gélida rigidez del General, que era como el núcleo frío, capaz de formar haciendas y regimientos que lo envolverían para protegerlo, y de imponer su orden helado, una simétrica estabilidad de cementerio" (184). La novela termina así con la muerte, debido a la imposibilidad de imaginar una exterioridad a una construcción esencialista y cerrada de la identidad nacional, en "la certeza de que era inútil tratar de abrirse paso hacia fuera, sencillamente porque ya no había ningún afuera, porque esa gruta negra se lo tragaba todo y la noche helada, la noche del General, volvía a extenderse por todas partes" (185).

\section{YGDRASIL}

En Ygdrasil todas las urbes representadas -Santiago de Chile, Puebla, Ciudad de México, la Chrysler con su Sección 14- son distópicas. Mariana, la protagonista, huye de cada una de ellas, pero no encuentra verdadera salida, pues cada nuevo espacio, aparentemente más abierto, representa, como en un video juego que se estructura en distintos niveles de complejidad pero siempre manteniendo el marco, un estadio más sofisticado de encierro.

El primero de estos lugares, Santiago, es el pasado, respecto del cual la nostalgia está completamente negada, pues es la ciudad del horror, de donde lo único posible es huir: en ella la madre de Mariana y la propia Mariana han 
sido explotadas por el padre, quien las ha convertido en esclavas sexuales. En particular la madre fue una "perra", "un producto artesanal típico de los suburbios de Santiago de Chile" (43), que consiste en mujeres que han sido mutiladas para cumplir más eficientemente sus funciones: les han cortado las extremidades, extraído todo lo aprovechable para el mercado de órganos y "freído el cerebro". De este horror la protagonista huye tanto territorial como corporalmente: viaja a México, trabaja como asesina a sueldo que se especializa en matar hombres y se evade en la droga. Así, en el inicio de la novela, va desde Puebla al Distrito Federal, el cual es descrito como una "enorme costra metálica, ingobernable y llena de laberintos"(12). A esta representación se suma la de la proliferación rizomática, a través de la imagen del tumor: "un quiste inverosímil". Aunque la novela no se detiene mayormente en la capital azteca, estas estructuraciones espaciales iniciales adelantan la representación de lo que serán los principales escenarios de la novela, la Sección 14 de la Chrysler y el ciberespacio, donde se encuentran el Ygdrasil y su centro, "la aberración", a los que me referiré más adelante.

Volviendo a la capital mexicana, ésta aparece como un híbrido, mezcla de artificial y natural, de inhumano y humano, de animal y humano, de moderno y primitivo, lo cual es, debido a la heterogeneidad y la mezcla de códigos, otro acercamiento al rizoma ${ }^{19}$ :

desde el cielo aparecía como una monstruosa ameba metálica engarfiada a la tierra, semejante a un parásito gris que emanara calor y ruido electrónico. Las carreteras que se enterraban en sus costados no cesaban de inyectarle vegetales, trozos de animales, madera y combustibles que la ciudad devoraba y degradaba, generando más y más calor. Era una reina monstruosa y obesa, incapaz de moverse, voraz e insaciable, sudando y defecando sin parar (12-13).

\footnotetext{
${ }^{19}$ Estas características se sintetizan en la siguiente cita de "Rizoma": "Resumamos los caracteres principales de un rizoma: a diferencia de los árboles o de sus raíces, el rizoma conecta cualquier punto con otro punto cualquiera, cada uno de sus rasgos no remite necesariamente a rasgos de la misma naturaleza; el rizoma pone en juego regímenes de signos muy distintos e incluso estados de no-signos. El rizoma no se deja reducir ni a lo Uno ni a lo Múltiple. No es lo Uno que deviene dos, ni tampoco que devendría directamente tres, cuatro o cinco, etc. No es un múltiple que deriva de lo Uno, o al que lo Uno se añadiría $(n+1)$. No está hecho de unidades, sino de dimensiones, o más bien de direcciones cambiantes. No tiene ni principio ni fin, siempre tiene un medio por el que crece y desborda. Constituye multiplicidades lineales de $n$ dimensiones, sin sujeto ni objeto, distribuibles en un plan de consistencia del que siempre se sustrae lo Uno" (n-1) (Deleuze/Guattari, 2006: 25).
} 
A esta descripción que la concibe como un monstruo mezclado, una suerte de Frankenstein hecho de fragmentos pertenecientes a distintos órdenes proyectados en la urbe, se suma un poco más adelante una imagen que la acerca a los regímenes despóticos de la Antigüedad y en particular a la ciudad cuya representación ambigua mezcla el pecado (la torre de Babel) y la maravilla (los jardines colgantes) que, no obstante, en la novela es convocada sólo en sus asociaciones con la tiranía: "Babilonia monstruosa, tejida estrato sobre estrato con fibra óptica, hormigón y huesos humanos" (14).

La descripción que le otorga vida a los espacios se profundiza en el caso del Banco de México, en el que Mariana recibe la orden de infiltrarse. El "dragón Mésico" -como lo nombra el título arcaizante del capítulo dos (todos los títulos imitan el estilo de las crónicas coloniales)- es, nuevamente, una mezcla de animal y tecnología, con sus "mandíbulas de acero" (23), su "uretra" y su sistema nervioso: "la médula, de ocho metros de diámetro, se extendía por toda la edificación, conectando los pisos y coordinando todas las funciones biológicas y administrativas de la empresa. Era el sistema neurovegetativo de una nueva generación de edificios vivos, monstruosas neuronas de exoesqueleto metálico llamadas colmenas" (24). En esta construcción híbrida, como corresponde a una vaquera de consola de ciberpunk o a un detective de serie negra, Mariana logra infiltrarse, pero es traicionada y entregada por quienes le han encargado el trabajo. La demostración del poderío del sujeto sobre el edificio vivo merece un castigo supremo: Mariana es fragmentada y violada por un grupo de ejecutivos del Banco de México o "devorada sin preguntar", como reza el título. No obstante, en lo que será la primera de una serie de muertes, logra reconstruirse gracias a la ayuda mágica, para pasar, después de algunas peripecias, a un nuevo espacio, perfectamente distópico, la Chrysler, y, dentro de ella, a la Sección 14.

La Chrysler es una multinacional pionera en el desarrollo del transporte de datos en el ciberespacio y en conectividad, que luego de comprar una gran extensión marítima ubicada entre el golfo de México y África, ha creado un estado nacional basado en un modo de producción esclavista. Como explica el narrador, "La Chrysler no era simplemente una compañía de transporte de dimensiones descomunales, sino una empresa con características de estado soberano: gozaba de fuero dentro de sus instalaciones, otorgaba documentos de identidad" (78). La Sección 14 es el corazón del sistema, con sus navegantes ciberespaciales -conectados y en trance, gracias a que se les suministra mezcalina, y que viven en promedio 35 años- y su culto religioso sadomasoquista, liderado por el jefe del sindicato, el Imbunche ${ }^{20}$.

\footnotetext{
${ }^{20}$ En un artículo todavía no publicado, cuyo título es "Más allá del sujeto fragmentado. Las aventuras de la identidad en Ygdrasil de Jorge Baradit", analizo el Imbunche y su culto.
} 
La descripción rizomática de este espacio se percibe en su proliferación. Así, se dice que dentro de la Chrysler la sección de los navegantes es también una unidad territorial mayor: "El complejo de edificaciones que componían la Sección 14 tenía la superficie de un país pequeño, con climas y microclimas" (167). Tal como en la capital mexicana, se insiste en la mezcla de lo inanimado con lo animal, de manera que nuevamente se trata de un espacio vivo, donde los códigos se mezclan: "Los edificios eran módulos blandos, mezcla de estructura sólida y tejido orgánico (...). Vigas de cartílago, estructuras óseas similares a costillas y puntales de acero sostenían los módulos habitables, que brotaban entre los tendones y órganos de las construcciones" (167). En esta suerte de pequeño país, la edificación monumental, unida a la organización caótica, es un indicio de su sistema político despótico, donde los deseos de los poderosos no tienen límites cuando se trata de explotar a los más débiles, de la cual da cuenta el primer recorrido que hace Mariana por la ciudad. La mujer pasea por el centro cívico, visita una suerte de mercado, compra algunos recuerdos, se detiene a mirar el espectáculo de un saltimbanqui y se siente "protegida y en paz". Se sienta a descansar en las escaleras de un edificio y ve a una niña sola y asustada que llora. Intenta protegerla, pero unos guardias la golpean y se llevan a la niña. Cuando, poco después, recupera la conciencia, y pregunta por ella, se le informa lo siguiente: "-Se la llevaron a Reubicación. Normalmente terminan como entretención de jefes de seguridad y miembros de la directiva del sindicato. No viven mucho -dijo uno de los guardias, con pasmosa naturalidad" (17071). De este modo, Mariana es rápidamente desengañada: su sensación de felicidad era sólo una apariencia, un sueño ilusorio que no tarda en evaporarse, lo que se confirma en el acontecer que resta, pues, a partir de este momento, se volverá prisionera del Imbunche. La arquitectura del templo de éste, cuyas paredes están tapizadas por trozos de carne podrida y cuyo piso está cubierto de seres humanos que el profeta pisa, da cuenta, ahora sin lugar a dudas, del sistema esclavista en el que Mariana se encuentra. Al igual que la niña, Mariana pasa a ser una pieza, primero del engranaje de la guerra santa del Imbunche, la cual es a su vez una pieza del proyecto de los misteriosos Perfectos destinado a construir un árbol "luciferino" (212), el "golem impostor, el futuro líder de la rebelión contra el dios agónico" (270), el Ygdrasil. Éste es el origen de Internet: "Ygdrasil fue el corazón remoto de Arpanet" (205) y "Los grupos económicos mundiales fomentan el desarrollo de internet. Tras ellos, los Perfectos buscan reproducir a escala planetaria la estructura neuronal de un santo" (205).

Hacia el final de la novela, Mariana debe ingresar en el ciberespacio que es el Ygdrasil, el cual es la última cárcel, de la cual no hay salida. Entonces, se da cuenta de que ha sido un ratón en un laberinto: "-No tenemos alternativa. Lo sé. Nunca la tenemos. Me siento como un ratón de laboratorio. Me abren una 
puertecita y yo entro por ahí, luego me abren otra y, si no entro, me ponen un electrodo en el culo hasta que lo hago; así de simple” (224). El laberinto que Mariana ha sido obligada a seguir sin darse cuenta, que es el laberinto de la novela, con sus peripecias y aventuras, es binario, con una dirección única. Tan único que ni siquiera la muerte es una posibilidad de salida, como lo muestra el que Mariana sea revivida varias veces en el relato, como personaje de videojuego pero también como pieza esencial que no puede faltar en el proyecto. No obstante, hay en la novela una representación de un segundo tipo de laberinto, el rizomático, que ya había aparecido en las imágenes híbridas de Ciudad de México y que ahora es asociado al Ygdrasil, específicamente al espacio denominado "La Aberración":

La zona del Ygdrasil conocida como La Aberración es un edificio que creció descomunalmente hacia un costado como efecto de un error administrativo. Los sucesivos errores y decisiones apriorísticas operaron como un cáncer. Se trata de un tumor que el Directorio interpretó como una señal divina. Los extraños niveles y hangares de dimensiones equívocas, contenidos unos dentro de otros y conectados a fuentes de datos sin concierto aparente, fueron llenados de personal heterogéneo asignado a tareas absurdas (...).

La Aberración terminó constituyéndose en un tipo de sistema neurovegetativo para el Ygdrasil (...). Su última etapa, la corteza, contiene los procesadores que finalmente consiguieron integrar la totalidad de los sistemas del Ygdrasil (209-210, los destacados son míos).

Se trata, entonces, de una representación rizomática -que coincide con las que se hacen de Internet como una multiplicidad de conexiones imposible de ordenar de manera jerárquica $y$, por tanto, de someter a un control central- ${ }^{21}$ sólo que en $Y g d r a s i l$ esta figura es parte de un complot destinado a esclavizar al ser humano a la tecnología, en función de un proyecto apocalíptico y sublime ${ }^{22}$, el de los misteriosos Perfectos, que está más allá de sus intereses y de su comprensión.

Las novelas estudiadas dibujan así un trayecto que va desde la ciudad distópica, convertida en ghetto, al espacio abierto utópico, al cual se renuncia; desde la ciudad y la nación que se desintegran al imposible mundo rural premoderno, del cual no hay regreso; desde la ciudad que esclaviza, con restringidas posibilidades de huida, al ciberespacio como una esclavitud tecnológica definitiva. Recorren, de esta manera, un camino similar al que

\footnotetext{
${ }^{21}$ Ello daría sustento a posibilidades emancipadoras, de las cuales serían un ejemplo los movimientos antiglobalización.

${ }^{22} \mathrm{Me}$ refiero a lo sublime posmoderno, planteado por Jameson (1991) en su libro sobre el posmodernismo.
} 
Paul Virilio visualiza en las últimas décadas en el orden mundial: el repliegue de los esfuerzos dirigidos a la conquista espacial y la conclusión exitosa de la colonización de la Tierra, que ponen al cuerpo humano como blanco de una endocolonización:

Las tecnociencias se precipitan sobre el cuerpo de este hombre-planeta ingrávido y al que ya nada protege verdaderamente, ni la ética ni la moral biopolítica. Por no poder escapar de nuestra biosfera natural, se va a colonizar, como tantas veces ya, un planeta infinitamente más accesible, el de un cuerposin-alma, cuerpo profano, para una ciencia sin conciencia que no ha dejado de profanar el espacio del cuerpo del animal, del esclavo o del colonizado de los imperios de antaño (1996: 123).

En este sentido es sintomático que de las tres novelas analizadas, la única que usa como parte de su escenario el espacio exterior, sea la primera, El ruido del tiempo, y que incluso en ella se represente la renuncia a esta utopía, con el cierre de las ventanas de la nave y el regreso a la Tierra. A partir de esto, ninguno de los otros dos relatos considerados en este trabajo se aventura más allá de los límites planetarios y el último -Ygdrasil- se centra en el cuerpo como territorio colonizado.

Para finalizar, el espacio del laberinto, presente en las tres novelas, me permite ejemplificar lo que he sostenido. En El ruido del tiempo, los rebeldes construyen un laberinto rizomático como una estrategia para llegar al Búnker de Coridra y destruirlo; en 2010: Chile en llamas, el laberinto binario es el camino que conduce a los personajes al centro de la hacienda, en el cual son atrapados por la identidad nacional monolítica y congelada expresada por el cadáver del General, cuya fascinación los lleva a la muerte; en Ygdrasil, la protagonista se piensa a sí misma como un ratón de laboratorio obligada a desplazarse por un laberinto sin salida, mientras que el Ygdrasil aparece como un laberinto rizomático, donde al sujeto no le queda más alternativa que acoplarse en cuerpo y alma, como una pieza a un proyecto tecnológico de conexión luciferino que lo esclaviza.

\section{REFERENCIAS}

Asensi, Manuel. 2003. Historia de la teoría de la literatura II: El siglo XX hasta los años setenta. Valencia: Tirant lo Blanch.

Baradit, Jorge. 2005. Ygdrasil. Buenos Aires: Ediciones B.

Borges, Jorge Luis. 1996. "Crónicas marcianas", en Obras Completas IV. Barcelona: Emecé, pp. 28-30. 
Debord, Guy. 2002 (1967). La sociedad del espectáculo. Prólogo, traducción y notas de José Luis Pardo. Buenos Aires: Pre-Textos.

Deleuze, Gilles y Félix Guattari. 2001 (1975). Kafka: Por una literatura menor. México: Era.

2006 (1980). "Rizoma”, en Mil mesetas: Capitalismo y esquizofrenia. Trad. José Vázquez Pérez. Valencia: Pre-Textos, pp. 9-32.

Eco, Umberto. 1987. "La línea y el laberinto: las estructuras del pensamiento latino", en Revista Vuelta, pp. 18-27. Disponible en: http://www.temakel.com/ texolvueco.htm. Acceso: octubre 2008.

Ferrer, Carolina. 2005. "Balcanización y orfandad en 2010: Chile en llamas de Darío Oses”. Documentos Lingüísticos y Literarios 28, pp. 29-33.

Foucault, Michel. 2001 (1982). "El sujeto y el poder", en Michel Foucault: más allá del estructuralismo y la hermenéutica. Hubert L. Dreyfus y Paul Rabinow. Trad. Rogelio C. Paredes. Buenos Aires: Ediciones Nueva Visión, pp. 241-259.

Freud, Sigmund. 1993. La interpretación de los sueños. Buenos Aires: Ediciones porteñas.

Jameson, Frederic. 1982. "Progress versus Utopia; or, can we imagine the future ?", en Science Fiction Studies 9, pp. 147-158.

1991. (1984). El posmodernismo o la lógica cultural del capitalismo avanzado. Trad. José Luis Pardo. Barcelona, Paidós.

Jaque, Claudio. 1987. El ruido del tiempo. Santiago: Galinost.

Los Prisioneros. 1986. "El baile de los que sobran", en Pateando Piedras. Santiago: EMI.

Lizama, Jaime. 2007. La ciudad fragmentada. Espacio público, errancia y vida cotidiana. Santiago: Universidad Diego Portales.

Novoa, Marcelo. 2006. Años luz. Mapa estelar de la ciencia ficción chilena. Valparaíso: Puerto de Escape/Universidad de Valparaíso Editorial.

Oses, Darío. 1998. 2010: Chile en llamas. Santiago: Planeta.

Schoennenbeck, Sebastián. 2008. "La antropofagia: un re-puesta en escena para Casa de campo de José Donoso", en Actas, JALLA 2008.

Virilio, Paul. 1996 (1993). El arte del motor: aceleración y realidad virtual. Buenos Aires: Manantial. 